This item was submitted to Loughborough's Research Repository by the author.

Items in Figshare are protected by copyright, with all rights reserved, unless otherwise indicated.

\title{
Porosity and pore size effect on the properties of sintered Ti35Nb4Sn alloy scaffolds and their suitability for tissue engineering applications
}

PLEASE CITE THE PUBLISHED VERSION

https://doi.org/10.1016/j.jallcom.2017.10.026

\section{PUBLISHER}

(C) Elsevier

VERSION

AM (Accepted Manuscript)

\section{PUBLISHER STATEMENT}

This work is made available according to the conditions of the Creative Commons Attribution-NonCommercialNoDerivatives 4.0 International (CC BY-NC-ND 4.0) licence. Full details of this licence are available at: https://creativecommons.org/licenses/by-nc-nd/4.0/

\section{LICENCE}

CC BY-NC-ND 4.0

\section{REPOSITORY RECORD}

Torres-Sanchez, Carmen, John McLaughlin, and Andrea Fotticchia. 2019. "Porosity and Pore Size Effect on the Properties of Sintered Ti35nb4sn Alloy Scaffolds and Their Suitability for Tissue Engineering Applications". figshare. https://hdl.handle.net/2134/26913. 


\title{
Porosity and pore size effect on the properties of sintered Ti35Nb4Sn alloy scaffolds and their suitability for tissue engineering applications
}

\author{
C. Torres-Sanchez ${ }^{1}$ *, John McLaughlin ${ }^{1}$, Andrea Fotticchia ${ }^{1,2}$ \\ ${ }^{1}$ Wolfson School of Mechanical, Electrical and Manufacturing Engineering, Loughborough University, \\ Leics, LE11 3TU, UK \\ ${ }^{2}$ Centre for Biological Engineering, Loughborough University, Leics, LE11 3TU, UK
}

\section{Abstract}

Porous scaffolds manufactured via powder metallurgy and sintering were designed for their structure (i.e. pore size and porosity) and mechanical properties (stiffness, strength) to be controlled and tailored to mimic those of human bone. The scaffolds were realised to fulfil three main objectives: (i) to obtain values of stiffness and strength similar to those of trabecular (or spongy) bone, with a view of exploiting these as bone grafts that permit cell regeneration, (ii) to establish a relationship between stiffness, strength and density that allows tailoring for mass customisation to suit patient's needs; and (iii) to assess alloy cytotoxicity and biocompatibility via in vitro studies. The results obtained using a very low stiffness alloy (Ti35Nb4Sn) further lowered with the introduction of nominal porosity (30-70\%) with pores in the ranges $180-300 \mu \mathrm{m}$ and 300-500 $\mu \mathrm{m}$ showed compatibility for anatomical locations typically subjected to implantation and bone grafting (femoral head and proximal tibia). The regression fitting parameters for the linear and power law regressions were similar to those found for bone specimens, confirming a structure favourable to capillary network formation. Biological tests confirmed non-cytotoxicicity of the alloy. Scaffolds of porosity nominal 50\%vol and pore range 300-500 $\mu \mathrm{m}$ performed best in the adhesion and propagation assays due to a good balance between surface area and pore cavity volume.

\footnotetext{
*Corresponding author, email: c.torres@lboro.ac.uk, phone: (+44) 01509227518
} 
Keywords

TiNbSn, elastic modulus, compressive strength, spaceholder, relative density, trabecular bone

\section{Introduction}

In 2013 the orthopaedic trauma devices market was valued at $\$ 5.7$ billion and it is expected to grow further to $\$ 9.4$ billion by 2020 at an annual growth rate of $7.2 \%$ [1]. An increasing aging population, not only in developed countries but also through the urbanisation of emerging markets, together with obesity epidemics and advances in clinical research are fuelling the demand for these devices. At present patients who carry implants from bone grafting in load-bearing locations such as knee, hip, ankle, etc. are outliving them, and seniors $>70$ years expect a durable implant replacement that will continue maintaining their quality of life. Drawbacks to the current existing implants are 'loosening' effects due to (i) "stress shielding" (i.e. when the implant is stiffer than the bone itself, it bears the load, so bone remodelling is hindered and healing retarded as cell count decays [2]) and (ii) lack of appropriate osteoconductive paths that allow the bone-forming cells to migrate into the porous implant and reside there, with the desired side effect of locking the device in place. In order to overcome these limitations to create better performing and longer-lasting implants, there is a need for a design and manufacturing strategy that allows engineering of the macrostructure of the implant and permits the tailoring of its mechanical properties to match that of the patient's host tissue.

Solid titanium alloys have been proven to provoke implant loosening due to their high stiffness (compared to that of bone) and non-porous interfaces [3], and alloys containing vanadium, cobalt, chrome, and nickel have been discarded because the ions eroded from the implants enter the blood stream and produce toxic deposits in soft organs such as liver and kidneys [4]. Beta-alloys Ti-Nb-Sn have received much attention recently due to their 
bone tissue compatibility [5], good corrosion resistance when tested at body-like $\mathrm{pH}$ and temperature conditions [6], and their lower stiffness when compared to other ternary Ti alloys, with Ti35Nb4Sn having one of the lowest Young's modulus of the group [7, 8]. Low stiffness values are achieved by the stabilisation of $\beta$-phase Ti at the working temperature (i.e. body temperature). Elemental Ti at room temperature presents a $\alpha$-type crystal (hexagonal) configuration and at high temperatures it exhibits an allotropic $\beta$-phase (cubic crystal configuration) that can become stable at room temperature with the addition of $\beta$-phase forming and stabilising elements (e.g. Nb, Sn [8-11]), which achieves a reduction in the Young's modulus (i.e. from E $\sim 116 \mathrm{GPa}$ in $\alpha$-phase Ti alloys [12] to $\sim 40 \mathrm{GPa}$ in $\beta$-phase Ti alloys [8] - both fabricated by casting or melting and the latter cold rolled). The stiffness can be further lowered by introducing a porous structure. Techniques such as foaming or sintering with space holders have been reported in literature $[13,14]$. Shape holder materials such as ammonium hydrogen carbonate, urea, sodium fluoride and chloride, saccharose and PMMA have been used in the manufacture of porous materials to control porosity and pore size [14-18]. Examples of stabilised beta-alloys of Ti fabricated using powder metallurgy coupled with the space holder/sintering method in order to lower their stiffness and control their strength are Ti7.5Mo [19], Ti40Nb [20], Ti24Nb4Zr8Sn [21], Ti10Nb10Zr [22], and the namely-toxic Ti6Al4V [23] and TiNi [24]. The stiffness- and strength-to-weight ratios can thus be optimised to match the mechanical properties of bone and these cavities engineered to promote cell proliferation, which results in anchoring the bone graft in place to minimise loosening in the mid- to long-term.

There is a comprehensive set of data available on the mechanical properties of bone. Caution is advised when cross-comparing from studies undertaken using different measuring techniques as these influence the order of magnitude of the results $[25,26]$. Comparable values of elastic modulus and compressive strength have been reported in the ranges of 3$20 \mathrm{GPa}$, and 10-180 MPa, respectively [2, 27]. The elastic modulus of human bone tissue has been shown to depend strongly on anatomical location, bone tissue type (e.g. cortical or 
trabecular) [28], on the health of the individual [29], and to a lesser extent on gender or age $[30,31]$. These ranges are narrower for properties of trabecular bone in areas typically subjected to implantation of devices. Elastic moduli have been reported for femoral heads as 2.6-11.2 GPa [32], femoral neck 1.5-4.5 GPa [28], and proximal tibia bone 3.27-10.58 GPa [33]. Patients affected by osteoporosis or osteoarthiritis have been seen to show a decrease of $22 \%$ or $14 \%$, respectively $[29,34]$, in values for elastic moduli in compression. Femoral head subchondral bone plate elastic moduli as low as 3-10 GPa have been observed in patients more severely affected by these conditions [29]. Compressive strengths on femur head are in the range of 4-16 MPa, the lower values corresponding to an aged population [27], for femoral neck 11.5-23.6 MPa [35], and for tibial trabecular bone the range has been reported as 3-33 MPa [27].

Bone ingrowth requires that the bone graft is osteoconductive (i.e. it guides the bone ingrowth by providing cells with a structure/scaffold that promotes cell proliferation) so this shall lead to successful osseointegration of the implant, that is, sequential cell differentiation and maturation to create cells within the scaffold [36]. A definitive pore size value for optimal bone growth has not been agreed among researchers because it is not the sole factor for an enhanced bone healing effect. Other variables such as mechanical stiffness to provide a good mechanical matching between bone and bone graft (i.e. artificial implant), and surface chemistry and roughness to anchor and long-term attachment of cells, need also to be considered. However, the current consensus is that osteoblast migration into porous spaces occurs if the cavities are larger than $50 \mu \mathrm{m}$ [37]; for non-load bearing condition sizes should be $50-125 \mu \mathrm{m}$ [38], and for load-bearing applications the pore size range should be $50-500$ $\mu \mathrm{m}[39]$.

The purpose of the present study was to systematically study the effect of porosity and pore size on the mechanical properties of a reportedly low-stiffness $\mathrm{Ti}$ alloy (Ti35Nb4Sn) so that an optimum structure could be defined with a view of pursuing bioengineering applications by avoiding mechanical properties mismatching between the scaffold and the host bone 
tissue. Porous scaffolds spanning a broad range of porosity (30-70 \%vol) were manufactured in two pore size ranges (a lower range 180-500 $\mu \mathrm{m}$ and a higher range 300$500 \mu \mathrm{m})$ which were created in the sintered scaffolds by a space holder. Biological functionality was pursued so the scaffolds had to be non-cytotoxic as well as promoters of a good degree of cell adhesion and growth that could indicate promising qualities as osteoconductive and osteoinductive substrates.

\section{Materials and Methods}

\subsection{Porous scaffolds preparation}

Elemental powders of Ti (Alfa Aesar, USA, 99.5\% purity, $\leq 45 \mu \mathrm{m},-325$ mesh), Nb (Aldrich, Germany, $99.8 \%$ purity, $<45 \mu \mathrm{m},-325$ mesh) and Sn (Alfa Aesar, USA, $99.8 \%$ purity, $\leq 45$ $\mu \mathrm{m},-325$ mesh) were blended together according to the desired composition of Ti $61 \% \mathrm{wt}$, $\mathrm{Nb} 35 \%$ wt and Sn 4 \%wt. This alloy is referred as Ti35Nb4Sn thereafter. Mechanical alloying was performed in a planetary ball mill (Fritsch, Germany, Pulverisette 6 Monomill) under argon atmosphere and using stainless steel grinding bowl and balls (10 mm diam). The ball-to-powder weight ratio was 10:1. The milling was carried out at room temperature with a rotation speed of $200 \mathrm{rpm}$ for $12 \mathrm{~h}$. This preparation time was chosen in accordance with previous experimental work that focused on the influence of ball milling time and the quality of the resulting mechanically alloyed powder material [40]. An additive, $2 \%$ wt stearic acid $\left(\mathrm{CH}_{3}\left(\mathrm{CH}_{2}\right)_{16} \mathrm{COOH}\right)$, was included as a process control agent (PCA) to be absorbed on the surface of the metal particles and assist the development of a desired fine microstructure during ball milling as well as to prevent cold welding to the surface of the vessel and balls during milling. Previous studies have shown this \%wt to be a good compromised amount to promote cold welding without fracturing becoming the dominant effect [13].

The ball-milled powders were mixed with the space-holder material, urea $\left(\mathrm{CO}\left(\mathrm{NH}_{2}\right)_{2}\right)($ Fisher, UK, 99\% purity, in two particle size ranges: $180-300 \mu \mathrm{m}$ and 300-500 $\mu \mathrm{m}$ ). Given the particle 
size of the urea, the powder-to-space holder volume ratio used was adjusted in order to yield a certain porosity ratio value (nominally from $30 \%$ to $70 \%$ ). Therefore, both the pore size and the porosity ratio could be controlled independently. The powder/urea mixture was then uniaxially cold compacted at a pressure of $250 \mathrm{MPa}$ into cylindrical green compacts with a diameter of $16 \mathrm{~mm}$ and a height of $8 \mathrm{~mm}$. These were placed in a calcination oven, heated at $2{ }^{\circ} \mathrm{C} / \mathrm{min}$ from room temperature up to $250^{\circ} \mathrm{C}$ and kept at that temperature for $2 \mathrm{~h}$ to sublimate the space holders and leave voids behind. It was important to ensure this process did not happen too quickly as it could affect the integrity of the compacted cylinders and produce striations. The subsequent sintering took place in an atmosphere-controlled (argon) furnace (Lenton Thermal Designs, UK) previously vacuum-flashed thoroughly. The green compacts, with only the metal powders in the porous structure, were heated up to $1100{ }^{\circ} \mathrm{C}$ at a heating rate of $5{ }^{\circ} \mathrm{C} / \mathrm{min}$, and held at this temperature for $3 \mathrm{~h}$. The furnace was then allowed to cool to room temperature. Samples with no spaceholder were also manufactured following the same pressing/sintering process. These will be referred to as non-porous sintered scaffolds. All samples were wet ground and polished using a 240-grit silicon carbide cloth. Finally they were cleaned using acetone and soapy water in an ultrasonic bath for 5 min, and left to air dry. The specimen's surface was examined with a scanning electron microscope (FEI, USA, Quanta 3D FEG dual beam, $3.5 \mathrm{~nm}, 30 \mathrm{kV}$ ) and measurements performed.

\subsection{Characterisation of the alloy powders and sintered porous scaffolds}

Phase constituents in the ball-milled powders and sintered porous scaffolds were characterised using X-ray diffractometry (Bruker, USA, AXS D8 Advance glancing) with $1.5046 \mathrm{~nm}$ wavelength Copper $\mathrm{K}$ alpha radiation source. An organic contamination analysis (Exeter Analytical Inc, UK, CE440 CHN) was performed on the ball-milled and sintered powder to ascertain if any unwanted compound might have been present. A micro-CT (XTek, USA, CT bench-top) system equipped with a 160k eV X-ray source and a 12-bit CCD camera was used for inspection of the sintered scaffolds. The samples were scanned at 6 
$\mu \mathrm{m}$ resolution. VGStudioMax and Simpleware software were used for volumetric reconstruction.

\subsection{Mechanical testing}

The compression experiments were conducted at room temperature on a 3367 Instron testing machine. Each sample of $16 \mathrm{~mm}$ diam and $8 \mathrm{~mm}$ height was loaded and unloaded at a constant speed of $1 \mathrm{~mm} / \mathrm{min}$ between a minimum strain of $0 \%$ and a strain value which increased in $0.1 \%$ steps over consecutive loops to a $\varepsilon_{\max }$, being this $0.8 \%$ or before the yield point which initiated microcracking (or plastic deformation), whichever was reached first. Finally, the scaffolds were tested at a compressive rate of $1 \mathrm{~mm} / \mathrm{min}$ until collapse or plastic deformation to determine their stiffness in compression (i.e. elastic moduli) as well as their compressive strength at the end of their elastic region behaviour.

\subsection{In vitro studies}

2.4.1. Preparation of the scaffolds and cell culture

Scaffolds of of $16 \mathrm{~mm}$ diam and $8 \mathrm{~mm}$ height with nominal porosity $30 \%, 40 \%, 50 \%, 60 \%$ and $70 \%$ and a pore size in the range $300-500 \mu \mathrm{m}$ were sterilised in an autoclave and thoroughly rinsed in deionised sterile water and phosphate-buffered saline (PBS) solution. Culture media was prepared using EMEM (Sigma-Aldrich, UK) supplemented with 1\% Lglutamine, 1\% non-essential amminoacids and 10\% fetal bovine serum (FBS) (Lonza, UK). Human osteosarcoma osteoblasts (MG-63) were defrosted and seeded in standard flasks. They were incubated in a $5 \% \mathrm{CO}_{2}$ atmosphere at $37^{\circ} \mathrm{C}$.

\subsubsection{Cellular attachment and proliferation}

Scaffolds were placed in 24-multiwell plates and soaked in the culture media for $2 \mathrm{~h}$ waiting on cell seeding. When cells were approximately $70 \%$ confluent they were trypsinised and concentrated by centrifugation. $30 \mu \mathrm{L}$ cell solution was pipetted onto each scaffold surface at $2.3 \times 10^{4}$ cells/sample seeding density. Cells were let to adhere for $2 \mathrm{~h}$ and then scaffolds 
were moved into a new multiwell plate and soaked with $1 \mathrm{ml}$ of fresh medium. One scaffold per type was left unseeded. Wells of a 24-multiwell tissue culture plate (Nunc, Thermofisher Scientific, UK) were chosen as a positive control and were seeded with the same cell density. This 24-multiwell plate was chosen because the well's diameter matched that of the scaffolds (16mm). Culture medium was changed once every two days. Experiments were performed in triplicate.

\subsubsection{Alamar Blue assay for cell viability}

Alamar blue solution was prepared by adding 10\% Alamar blue dye (Life Technologies, UK) to the culture media to assess cell viability on days 1, 3 and 7. At each time point culture medium was removed from the scaffolds and control plates and replaced with the Alamar blue solution. Samples were incubated for $4 \mathrm{~h}$ at $37^{\circ} \mathrm{C}$ and $5 \% \mathrm{CO}_{2}$ atmosphere. Three 100 $\mu \mathrm{L}$ samples were taken from each well and pipetted into a 96-multiwell plate. The change in Alamar blue hue was detected using a fluorescence (544 nm ex., $590 \mathrm{~nm}$ em.) microplate reader (LabTech, Germany, FLUOstar Omega, BMG). For cells seeded in the wells and on the scaffolds the (mean) signal of blanks (i.e. Alamar blue solution incubated with unseeded samples) was subtracted from the fluorescence values. In this way any effect of the alloy on the assay could be identified.

\subsubsection{Toluidine Blue assay for cell adhesion}

Toluidine blue active solution was prepared by diluting Toluidine blue dye (Sigma-Aldrich, UK) in $1 \%$ deionised water. After the Alamar blue test was concluded at day 7 , scaffolds were washed in PBS twice or until removing any trace of Alamar blue solution. Scaffolds were submerged in the Toluidine solution, incubated for $10 \mathrm{~min}$ at room temperature and then soaked in PBS twice to remove excess of Toluidine solution. The scaffold surfaces were photographed with a metallographic optical microscope (Olympus, Japan, BX60M).

\subsubsection{Statistical analysis}


Statistical analysis was performed using a two-way ANOVA with a Bonferroni correction post-hoc test. Differences at $p<0.05$ were considered statistically significant.

\section{Results}

The constituent elements, the powder after ball milling and after sintering were tested to identify the components in the sintered alloy (Figure 1). It can be observed in Figure 1d that the PCA (i.e. stearic acid) was completely removed from the mixing powders by the end of the ball milling process, so there was no organic contamination present in the powders. This was confirmed with a further $\mathrm{CHN}$ analysis. The results showed virtually no contamination ( $0 \% \mathrm{C} \pm 0.1 \%$ error, $0 \% \mathrm{H} \pm 0.1 \%$ error, $0 \% \mathrm{~N} \pm 0.3 \%$ error) in all the samples. The transformation from hexagonal $\alpha$-phase Ti into its cubic $\beta$-phase occurred during the sintering process due to the complete dissolution of the $\mathrm{Nb}$ and $\mathrm{Sn}$ elements into the $\beta$ phase. Some $\alpha$-phase Ti still remained, as can be seen in Figure 1e. This is thought to be due to the slow cooling rate in the sintering oven, which impeded the full retention of the $\beta$ phase deriving in an $\alpha+\beta$ alloy formed.

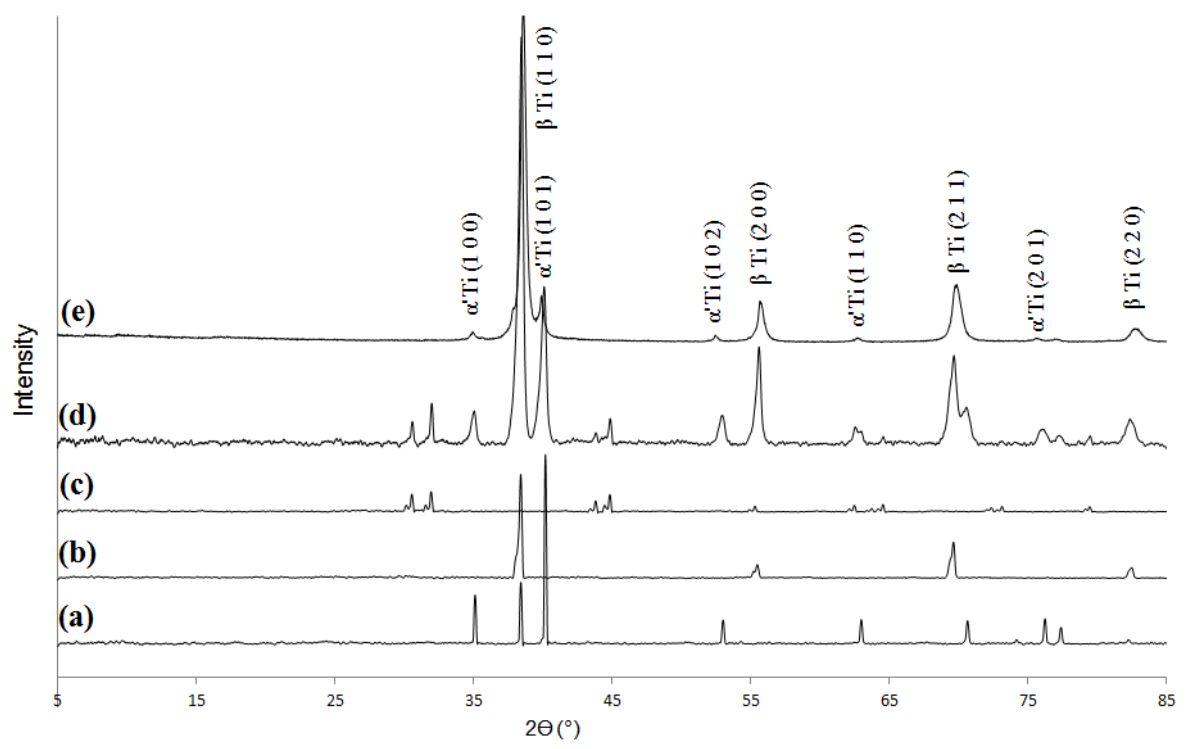

Figure 1: XRD patterns acquired from: constituent elements (a) Ti, (b) $\mathrm{Nb}$ and (c) $\mathrm{Sn}$, (d) mixed powders after ball-milling for $12 \mathrm{~h}$; (e) after sintering at $1100{ }^{\circ} \mathrm{C}$ for $3 \mathrm{~h}$ 
SEM images were used to measure actual pore sizes (Figure 2). Samples fabricated with urea crystals in the range $180-300 \mu \mathrm{m}$ presented pores of average values $257.44 \mu \mathrm{m}$ by 356.24 $\mu \mathrm{m}$ (standard deviation 71.84 and 93.99, respectively), and those in the range 300$500 \mu \mathrm{m}, 348.39 \mu \mathrm{m}$ by $489.78 \mu \mathrm{m}$ (standard deviation 106.71 and 148.52, respectively. These results were confirmed with microCT studies and volumetric reconstructions (Figure 3).

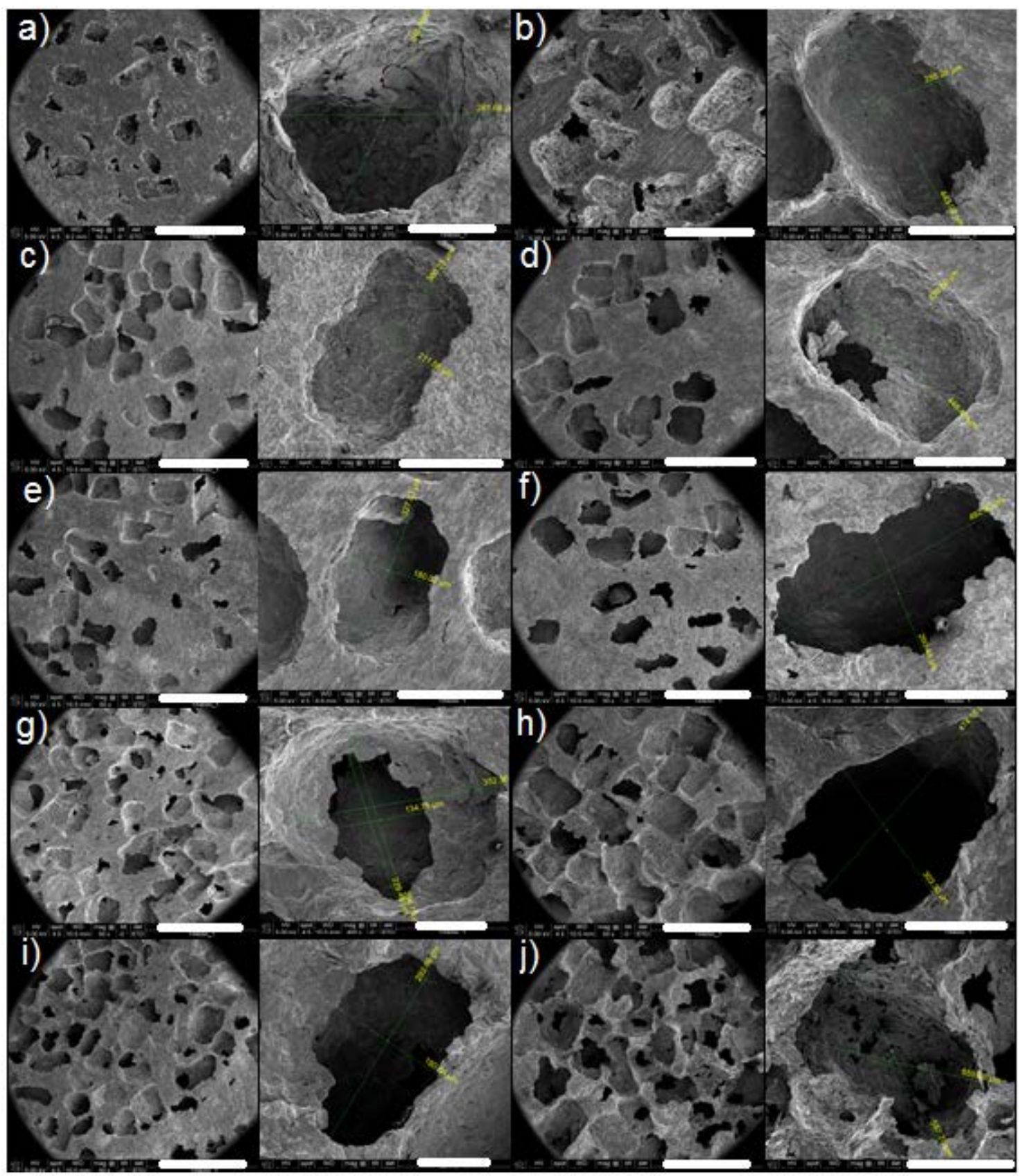

Figure 2: SEM images of scaffold surfaces for $30(a, b), 40(c, d), 50(e, f), 60(g, h), 70(i, j) \%$ nominal porosity fraction in the two space-holder size ranges: 180-300 $\mu \mathrm{m}(\mathrm{a}, \mathrm{c}, \mathrm{e}, \mathrm{g}, \mathrm{i})$ and 300-500 $\mu \mathrm{m}(\mathrm{b}, \mathrm{d}, \mathrm{f}, \mathrm{h}, \mathrm{j})$ and detailed pores (adjacent images). Scale bar: overall view 1mm; pore view $200 \mu \mathrm{m}$ 


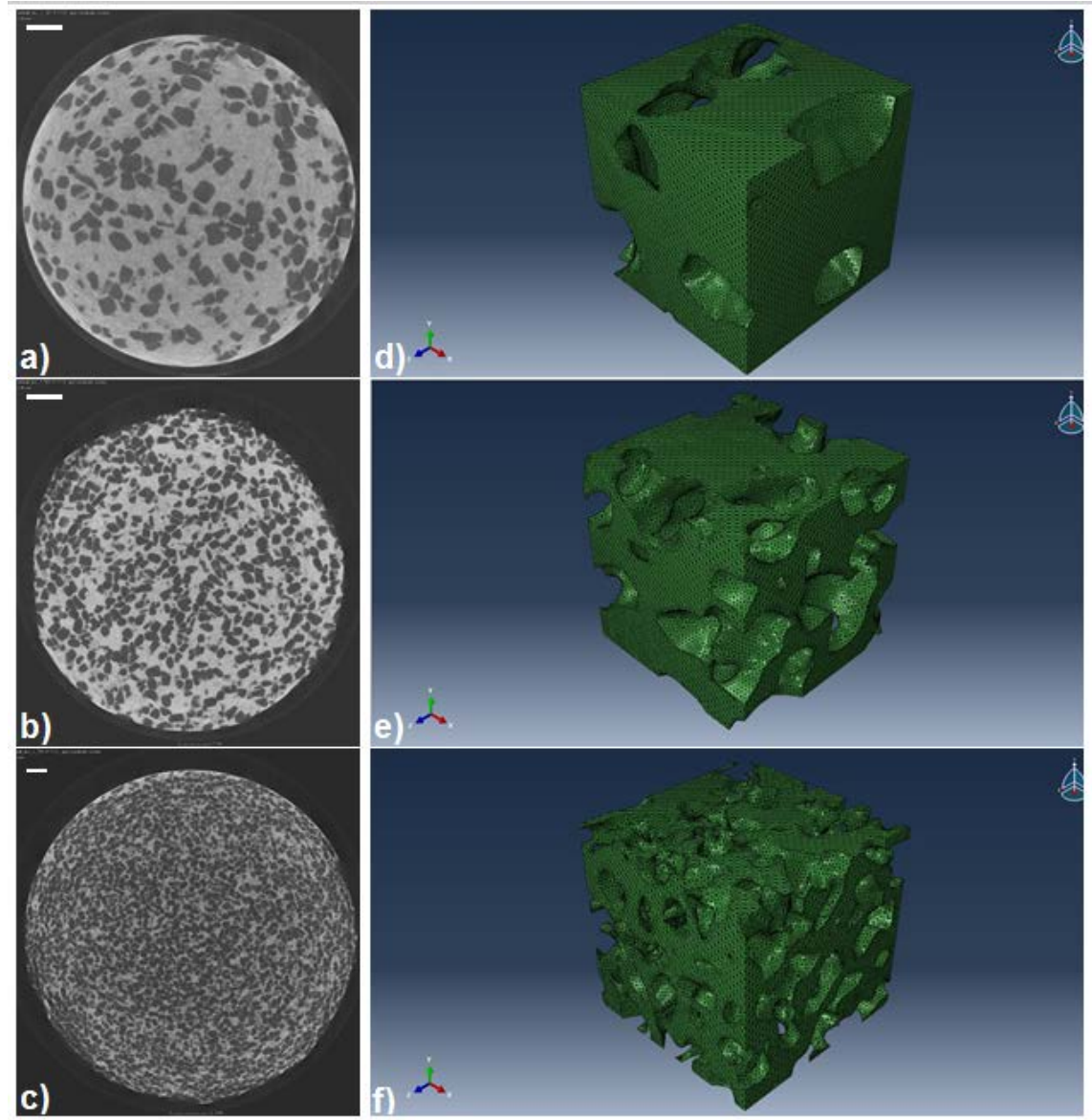

Figure 3: MicroCT slice of nominal $30(a, d), 50(b, e)$ and $70(c, f) \%$ porosity with pore range 300$500 \mu \mathrm{m}$ and a corresponding reconstructed cube section of side 100 voxels. Scale bar $1 \mathrm{~mm}$

The mechanical properties obtained from the tests (i.e. modulus of elasticity in compression, $\mathrm{E}^{*}$ and compressive strength at the end of the elastic region, $\sigma^{*}$ ) were compiled along with the experimental values of density and apparent porosity (\% vol) (Table 1$)$. The density $(\rho)$ was determined by the ratio of mass to volume and the apparent porosity as (1- $\left.\rho^{*} / \rho_{s}\right)$, being $\rho^{*}$ the density of a porous sample and $\rho_{s}$ that of a non-porous sintered sample. The compressive elastic moduli were calculated from the linear region of the destructive tests stress-strain plots, and the maximum compressive strength was read as the yield strength obtained using the $0.2 \%$ offset approach. Figure 4 shows the relationship between compression elastic moduli and maximum compressive strengths. 
Table 1: Results from scaffolds manufactured with a designed porosity and pore size to control mechanical properties

\begin{tabular}{|c|c|c|c|c|c|c|c|c|c|}
\hline $\begin{array}{l}\text { Pore agent } \\
\text { size }\end{array}$ & $\begin{array}{l}\text { Nominal } \\
\text { porosity, } \\
\text { \%vol }\end{array}$ & $\begin{array}{l}\rho^{*}, \\
\text { g/cm } \\
\text { (SD) }\end{array}$ & $\begin{array}{l}E^{*}, M P a \\
\text { (SD) }\end{array}$ & $\begin{array}{l}\sigma^{*}, \mathrm{MPa} \\
\text { (SD) }\end{array}$ & $\begin{array}{c}\text { Apparent } \\
\text { porosity, } \\
\% \text { vol (SD) }\end{array}$ & \multicolumn{2}{|c|}{$\begin{array}{l}\text { Linear regression }(y=a \cdot x+b), a, b \text {, } \\
\left(R^{2}\right)\end{array}$} & \multicolumn{2}{|c|}{$\begin{array}{l}\text { Power regression }\left(y=a \cdot x^{n}\right), a, n \text {, } \\
\qquad\left(R^{2}\right)\end{array}$} \\
\hline none & 0 & $\begin{array}{l}4.133 \\
(0.053)\end{array}$ & $\begin{array}{l}12280.87 \\
(109.119)\end{array}$ & $\begin{array}{l}164.960 \\
(8.845)\end{array}$ & inherent & & & & \\
\hline \multirow{5}{*}{$180-300 \mu \mathrm{m}$} & 30 & $\begin{array}{l}3.281 \\
(0.084)\end{array}$ & $\begin{array}{l}8629.87 \\
(978.64)\end{array}$ & $\begin{array}{l}140.053 \\
(31.031)\end{array}$ & $\begin{array}{l}20.982 \\
(2.013)\end{array}$ & \multirow{5}{*}{$\begin{array}{l}E: 1.350,-0.368 \\
(0.952)\end{array}$} & \multirow{10}{*}{$\begin{array}{l}\text { E: } 1.268,-0.313 \text {, } \\
(0.926)\end{array}$} & \multirow{5}{*}{$\begin{array}{l}\text { E: 1.192, 2.034, } \\
(0.916)\end{array}$} & \multirow{10}{*}{$\begin{array}{l}\text { E: 1.123, 1.829, } \\
(0.895)\end{array}$} \\
\hline & 40 & $\begin{array}{l}2.791 \\
(0.092)\end{array}$ & $\begin{array}{l}6138.13 \\
(1067.03)\end{array}$ & $\begin{array}{l}78.050 \\
(25.853)\end{array}$ & $\begin{array}{l}32.796 \\
(2.205)\end{array}$ & & & & \\
\hline & 50 & $\begin{array}{l}2.531 \\
(0.127)\end{array}$ & $\begin{array}{l}6277.37 \\
(610.43)\end{array}$ & $\begin{array}{l}65.797 \\
(13.874)\end{array}$ & $\begin{array}{l}39.950^{\dagger} \\
(3.057)\end{array}$ & & & & \\
\hline & 60 & $\begin{array}{l}2.056 \\
(0.125)\end{array}$ & $\begin{array}{l}4108.77 \\
(1116.52)\end{array}$ & $\begin{array}{l}37.123 \\
(8.498)\end{array}$ & $\begin{array}{l}50.486 \\
(3.016)\end{array}$ & & & & \\
\hline & 70 & $\begin{array}{l}1.845 \\
(0.126)\end{array}$ & $\begin{array}{l}2399.20 \\
(297.11)\end{array}$ & $\begin{array}{l}19.48 \\
(4.001)\end{array}$ & $\begin{array}{l}57.600^{\dagger} \\
(3.033)\end{array}$ & & & & \\
\hline \multirow{5}{*}{$300-500 \mu \mathrm{m}$} & 30 & $\begin{array}{l}3.269 \\
(0.248)\end{array}$ & $\begin{array}{l}9300.87 \\
(934.91)\end{array}$ & $\begin{array}{l}155.390 \\
(19.225)\end{array}$ & $\begin{array}{l}23.500^{\dagger} \\
(5.969)\end{array}$ & \multirow{5}{*}{ 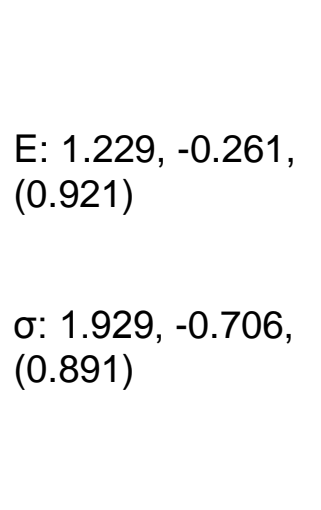 } & & \multirow{5}{*}{$\begin{array}{l}\text { E: } 1.008,1.659 \text {, } \\
(0.917)\end{array}$} & \\
\hline & 40 & $\begin{array}{l}2.972 \\
(0.093)\end{array}$ & $\begin{array}{l}6721.07 \\
(476.72)\end{array}$ & $\begin{array}{l}101.060 \\
(15.050)\end{array}$ & $\begin{array}{l}28.422 \\
(2.242)\end{array}$ & & & & \\
\hline & 50 & $\begin{array}{l}2.499 \\
(0.102)\end{array}$ & $\begin{array}{l}5960.93 \\
(802.82)\end{array}$ & $\begin{array}{l}56.213 \\
(10.977)\end{array}$ & $\begin{array}{l}39.400^{\dagger} \\
(2.448)\end{array}$ & & & & \\
\hline & 60 & $\begin{array}{l}2.101 \\
(0.245)\end{array}$ & $\begin{array}{l}5139.63 \\
(741.13)\end{array}$ & $\begin{array}{l}42.510 \\
(8.934)\end{array}$ & $\begin{array}{l}49.399 \\
(5.900)\end{array}$ & & & & \\
\hline & 70 & $\begin{array}{l}1.740 \\
(0.128)\end{array}$ & $\begin{array}{l}2796.13 \\
(1161.93)\end{array}$ & $\begin{array}{l}32.477 \\
(10.182)\end{array}$ & $\begin{array}{l}58.500^{\dagger} \\
(3.075)\end{array}$ & & & & \\
\hline
\end{tabular}

Confirmed with micro-CT results 


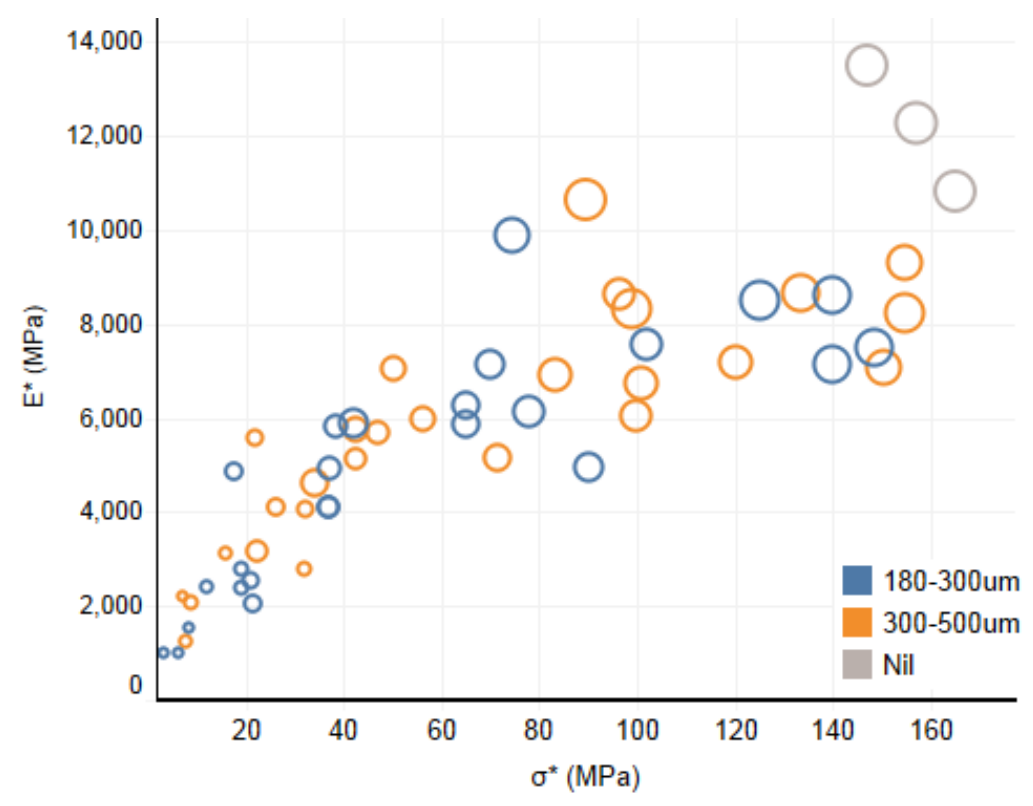

Figure 4: Compression elastic modulus versus compressive strength at yield point; blue dots for pore size range $180-300 \mu \mathrm{m}$ and orange for pore size range $300-500 \mu \mathrm{m}$; dot size is proportional to sample density

The ratios elastic modulus of the porous sample $\left(E^{\star}\right)$ to that of the solid sintered sample $\left(E_{s}\right)$ and compressive strength of the porous sample $\left(\sigma^{*}\right)$ to that of the solid sintered sample $\left(\sigma_{\mathrm{s}}\right)$ and the ratio of the porous sample density $\left(\rho^{*}\right)$ to that of the solid sintered sample $\left(\rho_{s}\right)$ were calculated and plotted (Figure 5).
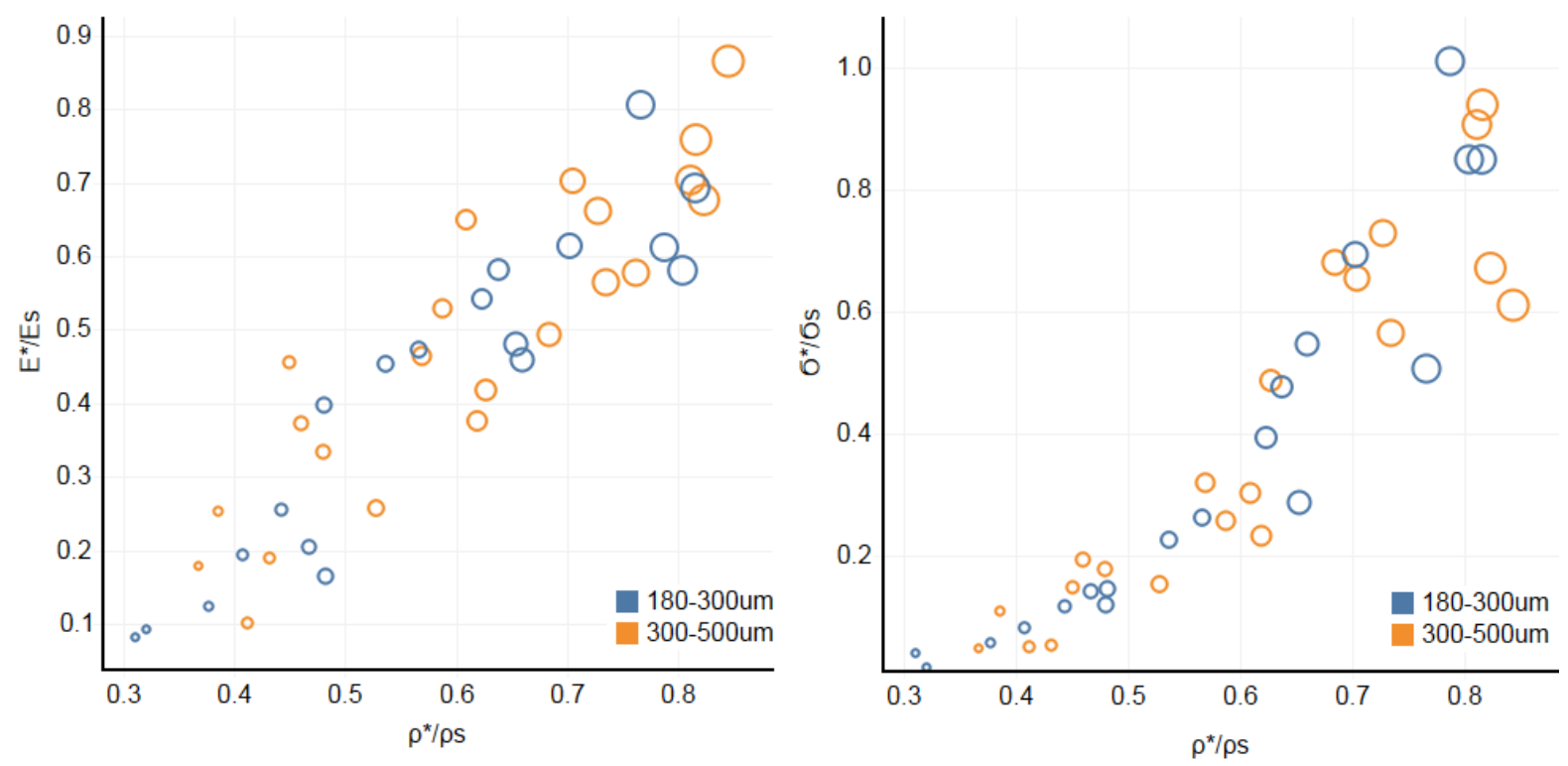

Figure 5: Elastic modulus ratio versus density ratio (left) and compressive strength ratio versus density ratio (right): blue dots for pore size range 180-300 $\mu \mathrm{m}$ and orange for pore size range 300-500 
Both a linear and a power relationship were studied between elastic modulus and density ratios. The results are listed in Table 1. Apparent porosity was measured by the ratio between the density of the porous scaffold and the density of the sintered sample with no incurred porosity. Results were confirmed via micro-CT studies. The set of results from the increasing strain test showed a higher elasticity for the samples with low nominal porosity and a low residual strain at the end of the final cycle can be observed (Figure 6). As porosity increased, the compressive stresses achieved were reduced for the same value of strain. Specimens of larger porosity and pore size presented a significant accumulated residual strain which indicated failure by microfracturing (Figure 6h and j). 


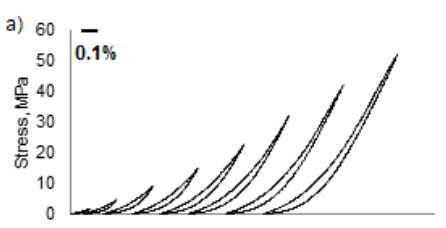

Strain, \%

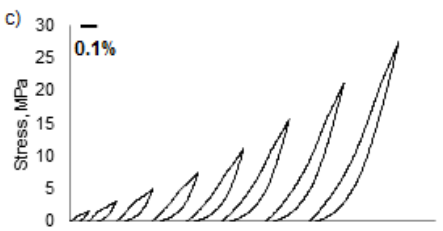

Strain, \%

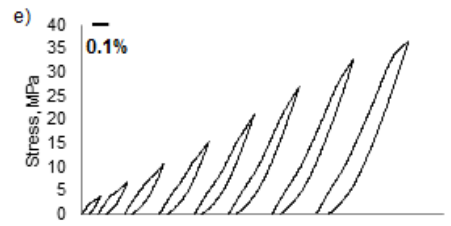

Strain, \%

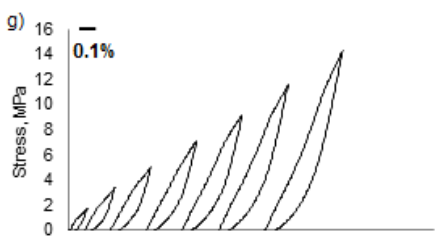

Strain, \%

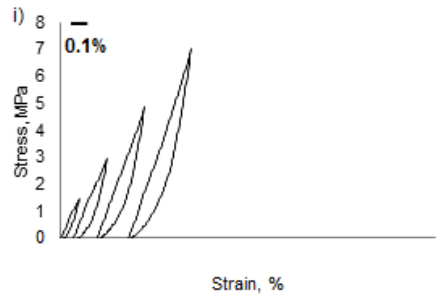

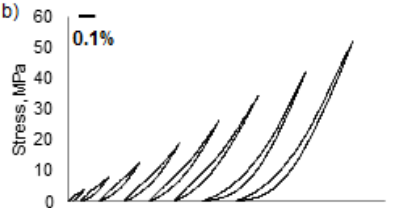

Strain, \%

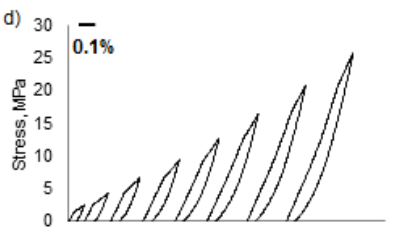

Strain, \%

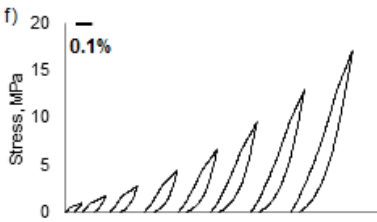

Strain, \%

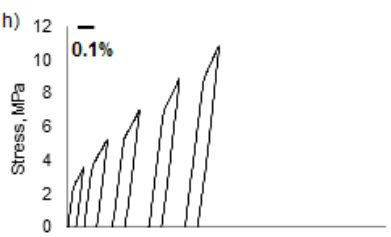

Strain, \%

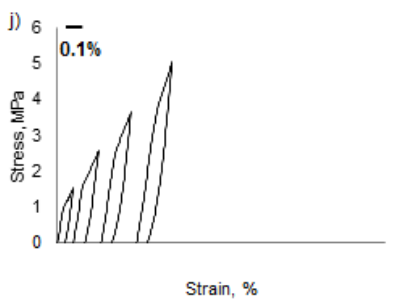

Figure 6: Increasing strain cycling tests from $0 \%$ at $0.1 \%$ intervals until $\varepsilon_{\max }(0.8 \%$ or until plastic deformation or microfracturing): nominal $30-70 \%$ porosity with pore range $180-300 \mu \mathrm{m}(\mathrm{a}, \mathrm{c}, \mathrm{e}, \mathrm{g}, \mathrm{i})$ and $300-500 \mu \mathrm{m}(b, d, f, h, j)$

Cell viability results via the Alamar blue assay are shown in Figure 7 . Cells grown in the control wells showed a significant higher viability when compared to cells seeded on the scaffold at time point day 1 . On day 3 , although viability on control wells was larger than that on scaffolds, cells cultured on the scaffolds presented a two-fold proliferation rate compared to the control. No significant difference between the scaffolds was identified. On day 7 cell viability results surpassed the value of the control in all cases. All samples except 30 and $70 \%$ exhibited significant difference $(p<0.05)$ with the control sample. Lower performance was detected for the (nominal) 30\% scaffold compared to the other scaffolds, and (nominal) $70 \%$ 
scaffold performed worse than (nominal) 40,50 and $60 \%$ porosity scaffold $(p<0.05)$. The (nominal) $50 \%$ scaffolds performed best on day 7 .

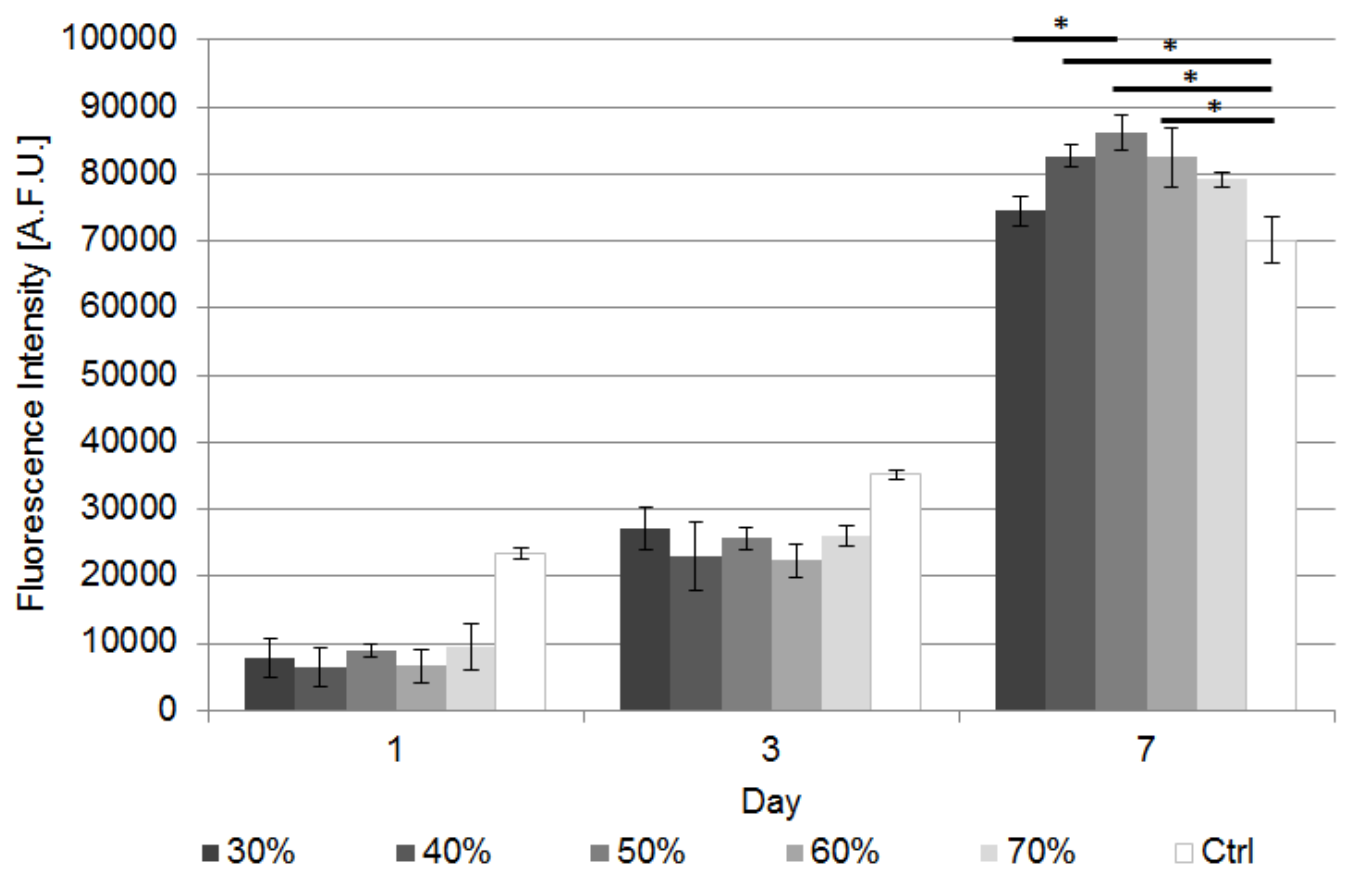

Figure 7: Viability of the osteoblasts evaluated with Alamar blue assay showing their adhesion to the substrates $(4 \mathrm{~h})$ and their proliferative capacity on days 1,3 and $7 .\left(^{*}\right)$ denotes $p<0.05$

Cell presence on the samples surface was assessed by the Toluidine blue test (Figure 8) and presented large blue-stained portions of their surface on the low porosity scaffolds, indicating cells growing on top of the scaffolds (Figure $8 \mathrm{a}, \mathrm{b}, \mathrm{d}, \mathrm{e}$ ). Conversely, pore staining dominated in high porosity scaffolds (namely nominal 50, 60 and 70\%) (Figure 8 h, k, n) leaving the surfaces with a similar hue of those scaffolds treated with toluidine blue but not seeded with cells (Figure $8 \mathrm{j}, \mathrm{I}, \mathrm{m}$ and o). Figure $8 \mathrm{~h}$ and Figure $8 \mathrm{k}$ show cell invasion into the pores (red arrows). Cells were difficult to observe with the microscope in scaffolds of nominal porosity $70 \%$ because of the short penetration distance of the light into the pores (Figure $8 \mathrm{n}$ ). Generally (nominal) 50\% scaffolds exhibited an intermediate performance between those of lower and higher porosities. 

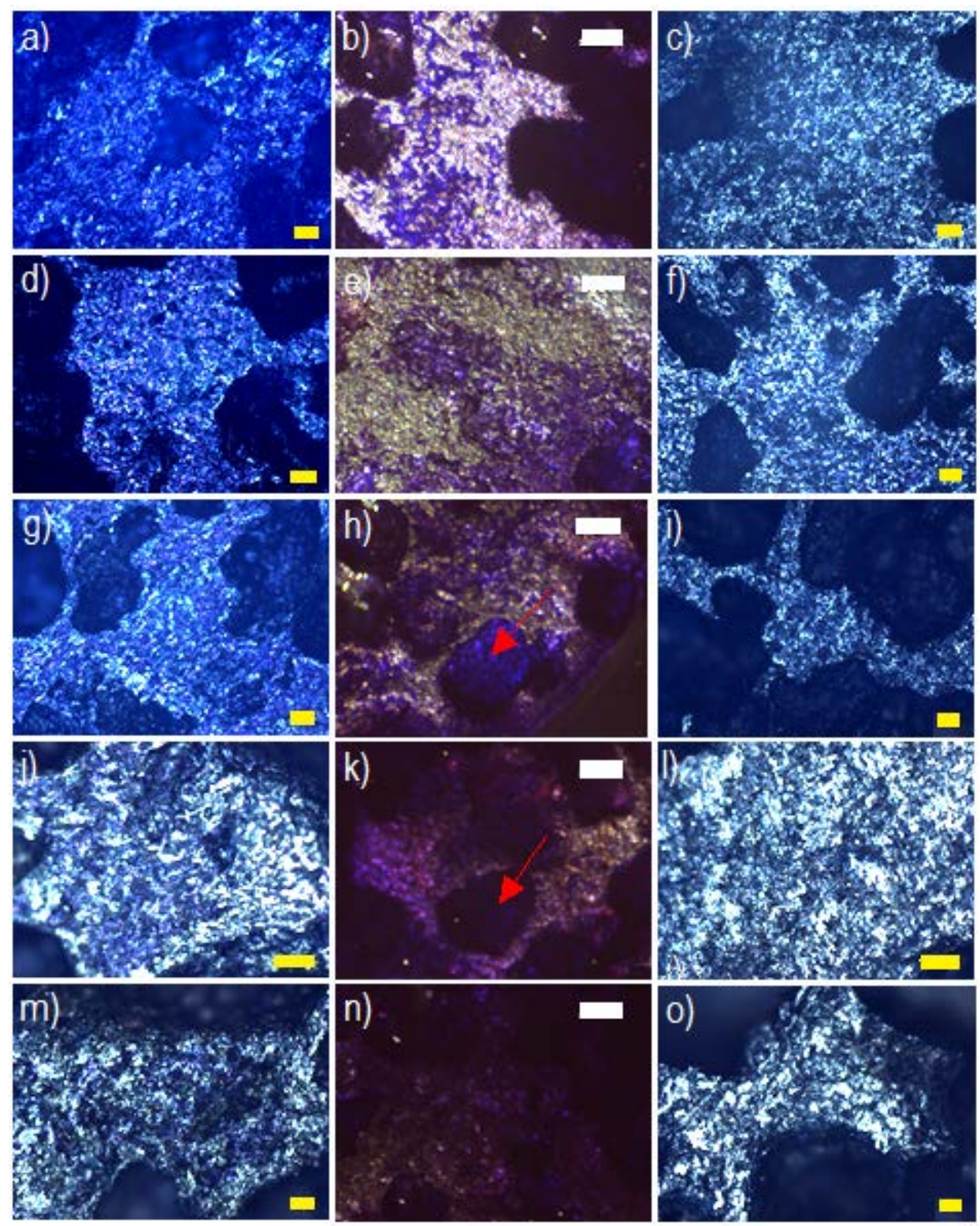

Figure 8: Toluidine blue assay results for cells cultured for 7 days. (a, $d, g, j$ and $m)$ show the surfaces of the scaffolds. Error bar $100 \mu \mathrm{m}$. (b, e, h k, and n) show the cells filter-highlighted. Error bar $200 \mu \mathrm{m}$.

(c, f, I, I and o) show unseeded scaffolds. Error bar $100 \mu \mathrm{m}$. Rows 1-5 correspond to nominal porosities $30-70 \%$, respectively

\section{Discussion}

In addition to using a namely "soft" TiNbSn alloy (i.e. Ti35Nb4Sn) for the manufacture of these scaffolds, the stiffness of the material was further decreased by introducing a volumetric porosity fraction. Both the porosity and the pore sizes were controlled with the presence of space-holders (i.e. urea) in different proportions and particle size range. Urea is a practical material as a space holder because it sublimates at approximately $133-135{ }^{\circ} \mathrm{C}$ during a calcination stage, unlike other space holders, e.g. $\mathrm{NaCl}, \mathrm{NaF}$ or saccharose, which 
require extra handling with dissolution in warm water for a number of hours. The voids left behind during calcination and the consolidated struts during sintering created the final porous architecture of the scaffold. The apparent porosity measured was lower than the theoretical nominal porosity which is explained by the presence of inherent closed porosity probably associated with the small pores present between partially densified green powders, which were of the size $\leq 45 \mu \mathrm{m}$. It was expected that pores would shrink during sintering leaving smaller spaces in the scaffold, however that effect did not occur. The expansion was even more pronounced in the smaller urea crystals range, exhibited by the larger-thanexpected dimensions of the pores at that range. It is suggested that the urea gas removal at calcination stage creates 'chimneys' for the gas to escape, enlarging in this way the existing cavities created.

The values obtained for the elastic moduli $(2.3-8.6 \mathrm{GPa})$ and the compressive strengths (19-155 MPa) match well to the data reported on trabecular bone, in particular those in anatomical locations where load-bearing bone grafting are typically performed (i.e. femoral heads and neck and proximal tibia). It is worth noting that comparisons to results obtained in other studies require caution because manufacturing processes may differ. Once the disparity between different measuring techniques is taken into account [41], the porous scaffolds manufactured via arc melting [8], laser melting [2] or electrical induction heating applying a load while sintering [42], which reduces the intrinsic porosity, are bound to exhibit higher elastic properties than those reported here via a purely thermal sintering process. Comparable studies on $\beta+\alpha$ Ti-based alloys manufactured via powder metallurgy and the spaceholder/sintering route have reported similar results. For example, reported values of elastic modulus and compressive strength, respectively, in porous scaffolds were: Ti7.5Mo (61-67\% porosity) $0.55-1.72$ GPa and $8.51-25.02 \mathrm{MPa}$ [19], Ti40Nb (36-80\% porosity) $1.5-3 \mathrm{GPa}$ and $10-35 \mathrm{MPa}$ [20], Ti6Al4V (43-64\% porosity) $1.42-14.76 \mathrm{GPa}$ and $28.2-$ $150 \mathrm{MPa}$ [23], Ti24Nb4Zr8Sn (17.6-46.8\% porosity) $1.54-6.66 \mathrm{GPa}$ and 30-325 MPa [21], 
Ti10Nb10Zr (porosity 59\%) 5.6 GPa and $137 \mathrm{MPa}$ [22], and TiNi (59-81\% porosity), 0.5 - 9 GPa and 5.8 - 93.2 MPa [24].

Studies on the mechanical response to cyclic loading were conducted up to a $0.8 \%$ strain through a stepwise increasing regime. The physiological yield strain on trabecular bone has been shown to be independent from anatomical site but dependant on individuals (i.e. (0.55$0.97 \%$ ) [28] and more typically $0.7 \%$ [35]). Specimens of normal porosity $30 \%, 40 \%$ and $50 \%$ showed good performance although the maximum stress reached decreased and residual strain accumulated with an increasing volumetric porosity. Specimens of $70 \%$ nominal porosity could not withstand applied strains beyond $0.4 \%$ without undergoing plastic deformation or microfracturing observed during and after the tests (i.e. local 'stepping' in the stress-strain plots and cracking or crumbling of some walls).

Theoretical research on porous materials provides correlations between porosity (or density) and mechanical properties of the porous materials with respect to those of the solid phase [43]. The main benefit offered by these relationships is the possibility of informing the design and manufacture of the porous scaffolds when specific strength and/or stiffness values are sought. In this way adjustable mechanical properties become feasible for the bioengineer. In this study properties of the non-porous sintered specimens have been considered to allow for a more representative ratio to the porous scaffold. With both manufactured through the same route and therefore inheriting the same continuum characteristics, they possess more in common than with an alloy fabricated through a very different approach (e.g. via casting). In [43], the elastic modulus is linked to the density through the following equation

$$
\frac{E^{*}}{E_{s}}=c_{1} \cdot\left(\frac{\rho^{*}}{\rho_{s}}\right)^{n}
$$

The ratio between the elastic modulus of the porous specimen $\left(E^{*}\right)$ and that of the sintered, non-porous $\left(E_{s}\right)$ specimen is proportional to the relative density of the porous specimen $\left(\rho^{\star}\right)$ 
to the non-porous specimen $\left(\rho_{\mathrm{s}}\right)$, with constants $\mathrm{c}_{1}$ and $\mathrm{n}$ as material characteristics. In particular $\mathrm{n}$ is an index in the range 1-3, being 1 for axially loaded channels, 2 for open cells, and 3 for cells loaded transversally [43]. Table 1 shows the results when fitting to linear and power correlations. The $\mathrm{n}$ index was in the range (1.3-1.8) which is indicative of an interconnected porous structure with a dominant network of channels in an open architecture. These structures are desired in scaffolds because they promote osteoconduction of cells and vascularisation (i.e. formation and connection of new blood vessels). These results are in agreement with other studies on porous scaffolds [14, 44] and on bone specimens [28, 45]. More specifically the $n$ index was (1.4-2.0) for the lower pore range and (1.2-1.6) for the larger pore range. This can be explained because, in addition to the creation of cavities per se, during the removal of space holders the material escaped from the solid creating channels, which are preferential paths when it comes to load transfer and liquid flow. The smaller pores presented a more tortuous architecture in which cell wall/strut bending dominates ( $\mathrm{n}$ index closer to 2), and larger pores presented a less intricate open channel layout, ideal for flow and more favourable to axial deformations.

The correlation between compressive elastic moduli and the 'yield' strength (i.e. the compressive strength displayed at the end of the elastic behaviour region) shows a powerlaw correlation in which the strength reached a plateau at a rate of approx. $1 / 2$ of the elastic modulus (i.e. $\left.E^{*}=58.188\left(\sigma^{*}\right)^{0.558}, R^{2}=0.856\right)$ instead of the expected linear correlation of an elastic behaviour under uniaxial compression, as per Hooke's law. This indicates that the strength in the specimens was lower for the level of stiffness exhibited. This is further demonstrated when comparing the porous/non-porous ratio of compressive strength $\left(\sigma^{*} / \sigma_{s}\right)$ against the corresponding ratio for densities $\left(\rho^{*} / \rho_{s}\right)$. The power trend returned a better fit. As per [43], 


$$
\frac{\sigma^{*}}{\sigma_{s}}=c_{2} \cdot\left(\frac{\rho^{*}}{\rho_{s}}\right)^{m}
$$

The $\mathrm{m}$ index was in the range (1.9-2.8). Although this experimental range is in agreement with others' work [44], m should have been 1.5 as in an open pore axially loaded structure behaving within a linear-elastic regime, in agreement with the elastic moduli and densities correlation. Power law correlations in trabecular bones have been found to report an $\mathrm{m}$ index in the range (1.49-2.18) [28, 35], which is lower than the values obtained in this study. This means that for the same $E^{*}$ obtained here there should be a corresponding stronger $\sigma^{*}$. Weaknesses in the inter-particle surfaces (e.g. particle contamination by oxidation or other surface contaminant from the powder fabrication process (for instance C) would hinder effective particle bonding) are suspected to be the reason for the lower-than expected values for compressive strength given the levels of $E^{\star}$. As already reported by other authors, it is difficult to achieve low elastic modulus simultaneously with high mechanical strength via powder metallurgy and sintering.

Specimens with a pore range $300-500 \mu \mathrm{m}$ were selected for the in vitro studies because the effect of pore size on osteointegration has been widely reported and concluded that typically cells do not span directly across gaps of less than $200 \mu \mathrm{m}$ [46], some indicated this is the lower threshold for in vivo osteoblasts proliferation [47], and gap lengths of approx. $400 \mu \mathrm{m}$ have been reported as most favourable [48].

In the viability study the cells seeded on the scaffolds for day 1 presented a lower fluorescence value, which is likely due to the low adherence onto the scaffolds at that time point. It was observed that some cells dropped from the scaffold to the bottom of the well after seeding. To avoid those cells' contribution to the overall signal, scaffolds were moved to new empty plates after $2 \mathrm{~h}$ of seeding and prior to the Alamar blue test. The viability rate increased two-fold and three-fold for days 3 and 7 respectively, when compared to the control. The slow propagation rate at early stages has also been studied as a function of 
locomotory parameters and the spatial distribution [49], which certainly affected the seeded cells in this study. This phenomenon can be explained by the low cell seeding density in which the cells required some time to activate physical contact signalling and after which they sustained standard exponential growth. This situation is thought to mimic in vivo implantation conditions and hence was preferred in this study. The (nominal) $50 \%$ porosity scaffolds present the highest levels of cell viability, with $30 \%$ being the lowest and $70 \%$ the second lowest (Figure 7). This result indicates that surface area, i.e. the true area created by the pores in the 3-dimensional space, is not the only driver at work when cells are proliferating and propagating. If that was the case, cell viability levels would correlate positively with apparent porosity (Table1). It appears as if in this case high levels of porosity (e.g. that measured in the nominal 70\%: $58.500 \pm 3.075 \%$ vol, ref Table 1) are unfavourable to the attachment of the cells, which could be washed off the very porous scaffold. On the contrary, the lowest level of porosity (e.g. nominal 30\%) exhibited the lowest level of cell viability, and incidentally it possessed the lowest surface area, cavity volume and also had the lowest value of measured apparent porosity (i.e. $23.500 \pm 5.969 \%$ vol, ref Table 1 ). An intermediate level of porosity (i.e. nominal 50\%) offered a favourable macrostructure for the cells to proliferate and attach, with sufficient surface area and cavity volume for a high population to be reached by day 7 and an apparent porosity measured at $39.400 \pm 2.448 \%$ vol, to support neighbourhoods of cells penetrating into the structure without percolating through the structure and out of the scaffold. This hypothesis is supported by the results from cell staining, as discussed next. From the Toluidine blue tests it can be concluded that cells grew on top of the scaffolds, mainly on 30 and $40 \%$ nominal porosity scaffolds (Figure 8 a, b, d, e), and preferred to migrate into pores when porosity was higher (i.e. 50, 60, 70\%) (Figure 8h). For the latter groups (i.e. higher porosity scaffolds) surfaces were found to be similar to those seeded with no cells (Figure $8 \mathrm{j}, \mathrm{I}, \mathrm{m}$ and o), which reinforces the argument that the majority of cell growth took place inside of the pores. This result agrees with other studies in which this porosity level is preferred for cell proliferation [50]. 


\section{Conclusions}

A good scaffold needs appropriate mechanical properties paired with good biological performance to ensure long-term successful implantation. The impact of the porous structure (i.e. porosity and pore size) on the mechanical behaviour was studied. Their porosity fraction was in this case controlled independently from pore size. Elastic modulus and compressive strengths were within range of those reported for trabecular bone in load-bearing anatomical sites (e.g. femur head and neck and proximal tibia). Linear and power law correlations confirmed an open pore structure that exhibited a combination of cell wall/strut bending and axial deformations when subjected to compression, and similar architecture and behaviour to those of trabecular bones. Fitting parameters that correlated the elastic modulus and the compressive strength to the relative density were experimentally determined. This is an important aspect for both the design and manufacturing processes because it adds an extra feature of flexibility in the tailoring of successful bone grafts for a receiving patient. In this way scaffolds' architecture can be designed by knowing the target values of the mechanical properties (i.e. those that match the host tissue).

The effect of the porous structure (i.e. porosity and pore size range) on cell response in the low stiffness biocompatible titanium alloys was tested via in vitro assays. The specimens were assessed for biological viability of the material, i.e. cytotoxicity, and its suitability for cell growth, which was studied in terms of cell uptake (i.e. whether cells have an affinity for the surface or pores in the structure). The cytotoxicity study confirmed that no toxic material leached from the scaffolds. Adhesion results showed scaffolds of nominal porosity $50 \%$ and pore size in the range $300-500 \mu \mathrm{m}$ as the most preferred architecture for cells that show an optimum viability value at the longest time point (i.e. 7 days) of the study. 
Acknowledgements:

The authors would like to thank Dr Keith Yendall at Loughborough Materials Characterisation Centre for SEM images, Dr Patricia D Sterpaio at Abertay University for micro-CT scanning and Dr Lee Margetts at University of Manchester and Alan Cheater for support in 3D reconstruction, and Dr Yang Liu for access to facilities to conduct biological viability study. Prof Paul P Conway has assisted with manuscript editing tasks.

Funding: This research did not receive any specific grant from funding agencies in the public, commercial, or not-for-profit sectors.

References:

[1] PersistenceMarketResearch, Global market study on orthopedic trauma devices, www.persistencemarketresearch.com PMPPEP2895 (2014) 91.

[2] B.V. Krishna, S. Bose, A. Bandyopadhyay, Low stiffness porous Ti structures for load-bearing implants, Acta Biomaterialia 3(6) (2007) 997-1006.

[3] S.L. Zhu, X.J. Yang, M.F. Chen, C.Y. Li, Z.D. Cui, Effect of porous NiTi alloy on bone formation: A comparative investigation with bulk NiTi alloy for 15 weeks in vivo, Materials Science and Engineering: C 28(8) (2008) 1271-1275.

[4] M. Niinomi, Recent metallic materials for biomedical applications, Metallurgical and Materials Transactions A 33(3) (2002) 477-486.

[5] K. Miura, N. Yamada, S. Hanada, T.-K. Jung, E. Itoi, The bone tissue compatibility of a new Ti-Nb-Sn alloy with a low Young's modulus, Acta Biomaterialia 7(5) (2011) 2320-2326.

[6] Y.F. Zheng, B.L. Wang, J.G. Wang, C. Li, L.C. Zhao, Corrosion behaviour of Ti$\mathrm{Nb}-\mathrm{Sn}$ shape memory alloys in different simulated body solutions, Materials Science and Engineering: A 438-440(0) (2006) 891-895.

[7] H. Matsumoto, S. Watanabe, S. Hanada, Beta TiNbSn Alloys with Low Young's Modulus and High Strength, MATERIALS TRANSACTIONS 46(5) (2005) 1070-1078. [8] T.-K. Jung, H. Matsumoto, T. Abumiya, N. Masahashi, M.-S. Kim, S. Hanada, Mechanical Properties - Graded Ti Alloy Implants for Orthopedic Applications, Materials Science Forum 631-632 (2010) 205-210.

[9] Y.L. Hao, S.J. Li, S.Y. Sun, R. Yang, Effect of Zr and Sn on Young's modulus and superelasticity of Ti-Nb-based alloys, Materials Science and Engineering: A 441(1-2) (2006) 112-118.

[10] S.J. Li, T.C. Cui, Y.L. Hao, R. Yang, Fatigue properties of a metastable $\beta$-type titanium alloy with reversible phase transformation, Acta Biomaterialia 4(2) (2008) 305-317. 
[11] F. Sun, Y.L. Hao, S. Nowak, T. Gloriant, P. Laheurte, F. Prima, A thermomechanical treatment to improve the superelastic performances of biomedical Ti$26 \mathrm{Nb}$ and $\mathrm{Ti}-20 \mathrm{Nb}-6 \mathrm{Zr}$ (at.\%) alloys, Journal of the Mechanical Behavior of Biomedical Materials 4(8) (2011) 1864-1872.

[12] J.A. Davidson, A.K. Mishra, P. Kovacs, R.A. Poggie, New Surface-Hardened, Low-Modulus, Corrosion-Resistant Ti-13Nb-13Zr Alloy for Total HIP Arthroplasty, Bio-Medical Materials and Engineering 4(3) (1994) 231-243.

[13] A. Nouri, P.D. Hodgson, C.E. Wen, Effect of process control agent on the porous structure and mechanical properties of a biomedical Ti-Sn-Nb alloy produced by powder metallurgy, Acta Biomaterialia 6(4) (2010) 1630-1639. [14] J. Xiong, Y. Li, X. Wang, P. Hodgson, C.e. Wen, Mechanical properties and bioactive surface modification via alkali-heat treatment of a porous $\mathrm{Ti}-18 \mathrm{Nb}-4 \mathrm{Sn}$ alloy for biomedical applications, Acta Biomaterialia 4(6) (2008) 1963-1968.

[15] D.S. Li, Y.P. Zhang, X. Ma, X.P. Zhang, Space-holder engineered porous NiTi shape memory alloys with improved pore characteristics and mechanical properties, Journal of Alloys and Compounds 474(1-2) (2009) L1-L5.

[16] M. Köhl, T. Habijan, M. Bram, H.P. Buchkremer, D. Stöver, M. Köller, Powder Metallurgical Near-Net-Shape Fabrication of Porous NiTi Shape Memory Alloys for Use as Long-Term Implants by the Combination of the Metal Injection Molding Process with the Space-Holder Technique, Advanced Engineering Materials 11(12) (2009) 959-968.

[17] A. Bansiddhi, D.C. Dunand, Shape-memory NiTi foams produced by solid-state replication with NaF, Intermetallics 15(12) (2007) 1612-1622.

[18] J. Jakubowicz, G. Adamek, M. Dewidar, Titanium foam made with saccharose as a space holder, Journal of Porous Materials 20(5) (2013) 1137-1141.

[19] H.-C. Hsu, S.-C. Wu, S.-K. Hsu, T.-Y. Chang, W.-F. Ho, Effect of ball milling on properties of porous Ti-7.5Mo alloy for biomedical applications, Journal of Alloys and Compounds 582 (2014) 793-801.

[20] K. Zhuravleva, A. Chivu, A. Teresiak, S. Scudino, M. Calin, L. Schultz, J. Eckert, A. Gebert, Porous low modulus Ti40Nb compacts with electrodeposited hydroxyapatite coating for biomedical applications, Materials Science and Engineering: C 33(4) (2013) 2280-2287.

[21] X. Cheng, S. Li, Y.L. Hao, R. Yang, Fabrication and mechanical properties of porous Ti-24Nb-4Zr-8Sn alloy developed for biomedical application, 2012.

[22] X. Wang, Y. Li, J. Xiong, P.D. Hodgson, C.e. Wen, Porous TiNbZr alloy

scaffolds for biomedical applications, Acta Biomaterialia 5(9) (2009) 3616-3624.

[23] Z. Esen, Ş. Bor, Characterization of Ti-6Al-4V alloy foams synthesized by space holder technique, Materials Science and Engineering: A 528(7) (2011) 32003209.

[24] T. Aydoğmuş, Ş. Bor, Processing of porous TiNi alloys using magnesium as space holder, Journal of Alloys and Compounds 478(1) (2009) 705-710.

[25] J.Y. Rho, R.B. Ashman, C.H. Turner, Young's modulus of trabecular and cortical bone material: Ultrasonic and microtensile measurements, Journal of Biomechanics 26(2) (1993) 111-119.

[26] C.H. Turner, J. Rho, Y. Takano, T.Y. Tsui, G.M. Pharr, The elastic properties of trabecular and cortical bone tissues are similar: results from two microscopic measurement techniques, Journal of Biomechanics 32(4) (1999) 437-441.

[27] T.M. Keaveny, E.F. Morgan, G.L. Niebur, O.C. Yeh, Biomechanics of Trabecular Bone, Annual Review of Biomedical Engineering 3(1) (2001) 307-333. 
[28] E.F. Morgan, H.H. Bayraktar, T.M. Keaveny, Trabecular bone modulus-density relationships depend on anatomic site, Journal of Biomechanics 36(7) (2003) 897904.

[29] B. Li, R.M. Aspden, Mechanical and material properties of the subchondral bone plate from the femoral head of patients with osteoarthritis or osteoporosis, Annals of the Rheumatic Diseases 56(4) (1997) 247-254.

[30] A. Burstein, D. Reilly, M. Martens, Aging of bone tissue: mechanical properties, The Journal of Bone \&amp; Joint Surgery 58(1) (1976) 82-86.

[31] B. Martin, Aging and strength of bone as a structural material, Calcified Tissue International 53(1) (1993) S34-S40.

[32] P.K. Zysset, X. Edward Guo, C. Edward Hoffler, K.E. Moore, S.A. Goldstein, Elastic modulus and hardness of cortical and trabecular bone lamellae measured by nanoindentation in the human femur, Journal of Biomechanics 32(10) (1999) 10051012.

[33] K. Choi, J.L. Kuhn, M.J. Ciarelli, S.A. Goldstein, The elastic moduli of human subchondral, trabecular, and cortical bone tissue and the size-dependency of cortical bone modulus, Journal of Biomechanics 23(11) (1990) 1103-1113.

[34] R. Dickenson, W. Hutton, Stott, The mechanical properties of bone in osteoporosis, Journal of Bone \& Joint Surgery, British Volume 63-B(2) (1981) 233238.

[35] E.F. Morgan, T.M. Keaveny, Dependence of yield strain of human trabecular bone on anatomic site, Journal of Biomechanics 34(5) (2001) 569-577.

[36] T.A. Albrektsson, C.J. Johansson, Osteoinduction, osteoconduction and osseointegration, European Spine Journal 10(0) (2001) S96-S101.

[37] V. Karageorgiou, D. Kaplan, Porosity of 3D biomaterial scaffolds and osteogenesis, Biomaterials 26(27) (2005) 5474-5491.

[38] A.I. Itälä, H.O. Ylänen, C. Ekholm, K.H. Karlsson, H.T. Aro, Pore diameter of more than $100 \mu \mathrm{m}$ is not requisite for bone ingrowth in rabbits, Journal of Biomedical Materials Research 58(6) (2001) 679-683.

[39] D. Tadic, F. Beckmann, T. Donath, M. Epple, Comparison of different methods for the preparation of porous bone substitution materials and structural investigations by synchrotron $\mu$-computer tomography, Materialwissenschaft und Werkstofftechnik 35(4) (2004) 240-244.

[40] A. Nouri, P.D. Hodgson, C. Wen, Effect of ball-milling time on the structural characteristics of biomedical porous Ti-Sn-Nb alloy, Materials Science and Engineering: C 31(5) (2011) 921-928.

[41] C. Greiner, S.M. Oppenheimer, D.C. Dunand, High strength, low stiffness, porous NiTi with superelastic properties, Acta Biomaterialia 1(6) (2005) 705-716. [42] X. Wang, Y. Chen, L. Xu, S. Xiao, F. Kong, K.D. Woo, Ti-Nb-Sn-hydroxyapatite composites synthesized by mechanical alloying and high frequency induction heated sintering, Journal of the Mechanical Behavior of Biomedical Materials 4(8) (2011) 2074-2080.

[43] L.J. Gibson, M.F. Ashby, Cellular solids: structure and properties, 2nd ed., Cambridge University Press1997.

[44] W. Niu, C. Bai, G. Qiu, Q. Wang, Processing and properties of porous titanium using space holder technique, Materials Science and Engineering: A 506(1-2) (2009) 148-151.

[45] D.C. Wirtz, N. Schiffers, T. Pandorf, K. Radermacher, D. Weichert, R. Forst, Critical evaluation of known bone material properties to realize anisotropic FEsimulation of the proximal femur, Journal of Biomechanics 33(10) (2000) 1325-1330. 
[46] W. Xue, B.V. Krishna, A. Bandyopadhyay, S. Bose, Processing and biocompatibility evaluation of laser processed porous titanium, Acta biomaterialia 3(6) (2007) 1007-1018.

[47] J.-H. Kühne, R. Bartl, B. Frisch, C. Hammer, V. Jansson, M. Zimmer, Bone formation in coralline hydroxyapatite: Effects of pore size studied in rabbits, Acta Orthopaedica Scandinavica 65(3) (1994) 246-252.

[48] B. Chang, W. Song, T. Han, J. Yan, F. Li, L. Zhao, H. Kou, Y. Zhang, Influence of pore size of porous titanium fabricated by vacuum diffusion bonding of titanium meshes on cell penetration and bone ingrowth, Acta Biomaterialia 33 (2016) 311-321. [49] G. Cheng, B.B. Youssef, P. Markenscoff, K. Zygourakis, Cell Population Dynamics Modulate the Rates of Tissue Growth Processes, Biophysical Journal 90(3) (2006) 713-724.

[50] M. Bram, H. Schiefer, D. Bogdanski, M. Köller, H.P. Buchkremer, D. Stöver, Implant surgery: How bone bonds to PM titanium, Metal Powder Report 61(2) (2006) 26-31. 